\title{
Needlestick Safety and Prevention Act
}

\section{Mark F. Tatelbaum, JD}

The Needlestick Safety and Prevention Act to revise the Occupational Safety and Health Administration's (OSHA) standard regulating occupational exposure to bloodborne pathogens, including the human immunodeficiency virus, the hepatitis B virus, and the hepatitis $\mathrm{C}$ virus, was signed into law on November 6, 2000. OSHA published in the Federal Register its regulations reflecting the Act and its requirments. The effective date of the regulations is April $18,2001$.

The Needlestick Safety and Prevention Act seeks to further reduce health care workers' exposure to bloodborne pathogens by imposing additional requirements upon employers, such as hospitals and ASCs, concerning their sharps procedures. Consistent with the Act, OSHA's regulations (1) modify the definition of "engineering controls" and adds definitions for the terms "sharps with engineered sharps injury protection" and "needleless systems," (2) requires employers to consider and implement new technologies when they update their "exposure control plan," (3) requires employers to solicit employee input with respect to appropriate engineering controls, and (4) requires employers to maintain a sharps injury log.

Practical questions about implementing the new requirements are a source of major concern. The House Committee on Education and the Workforce stated in legislative history to the Act that the statute was not meant to disturb the underlying flexible, performance-oriented nature of the Initial Standard.

Keywords: Needle stick safety, bloodborne pathogens, health care workers, Occupational Safety and Health Administration
On November 6, 2000, President Clinton signed into law the Needlestick Safety and Prevention Act to revise the Occupational Safety and Health Administration's (OSHA) standard regulating occupational exposure to bloodborne pathogens, including the human immunodeficiency virus, the hepatitis B virus, and the hepatitis C virus. On January 18,2001 , OSHA published in the Federal Register its regulations reflecting the Act and its requirments. The effective date of the regulations is April 18, 2001. They impose additional administrative responsibilities in the way that hospitals, ambulatory surgical centers (ASCs), pain management practices, and other health care providers will manage their sharps protection procedures. The Act and the regulations will have a profound effect on interventional pain management.

From Arent Fox Klinter Plotkin \& Kahn, PLLC, Washington, DC. Mr. Tatelbaum is a Senior Associate in the Healthcare Group of Arent Fox. Address correspondence: William A. Sarraille, JD, 1050 Connecticut Avenue NW, Washington, DC 20036-5339.

\section{THE INITIAL BLOODBORNE PATHOGENS STANDARD}

OSHA issued the Initial Standard regulating occupational exposure to bloodborne pathogens in 1991. This standard applied to all occupational exposure to blood or other potentially infectious material. Occupational exposure was defined to mean "reasonably anticipated skin, eye, mucous membrane, or parenteral contact with blood or other potentially infectious material that may result from the performance of an employee's duties." The Initial Standard required employers to maintain certain procedures to protect their employees from contamination from bloodborne pathogens.

Specifically, the Initial Standard required employers to establish a written "Exposure Control Plan" designed to eliminate or minimize employee exposure. The Initial Standard required "engineering controls" to isolate or remove the bloodborne pathogen hazards from the workplace. It also required employers to review and update their Plan, at least annually and more often, as necessary, so that it reflects new or modified tasks and procedures which affect operational exposure and new or revised employee positions subject to occupational exposure. The Initial 
Standard also required that employers maintain accurate medical records for each employee with occupational exposure.

\section{THE NEEDLESTICK SAFETY AND PREVENTION ACT}

The Needlestick Safety and Prevention Act seeks to further reduce health care workers' exposure to bloodborne pathogens by imposing additional requirements upon employers, such as hospitals and ASCs, concerning their sharps procedures. Unless superceded by OSHA, the Act requires hospitals and ASCs, among others, to review and update their Plans to reflect changes in technology, consider and implement new technologies, solicit input from employees, and maintain a sharps injury log.

\section{THE REVISED STANDARD}

Consistent with the Act, OSHA's regulations (1) modify the definition of "engineering controls" and adds definitions for the terms "sharps with engineered sharps injury protection" and "needleless systems," (2) requires employers to consider and implement new technologies when they update their "exposure control plan," (3) requires employers to solicit employee input with respect to appropriate engineering controls, and (4) requires employers to maintain a sharps injury log.

\section{Definitions}

In the final rule, OSHA modifies the definition of the term "engineering control" to clarify that it includes all control measures that isolate or remove a hazard from the workplace, such as "sharps with engineered sharps injury protections," "needleless systems," and all other medical devices designed to reduce the risk of percutaneous exposure to bloodborne pathogens. OSHA defines the term "sharps with engineered sharps injury protection" as a nonneedle sharp or needle device used for withdrawing body fluids, accessing a vein or artery, or administering medications or other fluids, with a built-in safety feature or mechanism that effectively reduces the risk of an exposure incident. OSHA defines the term "needleless systems" as a device that does not use needles for: (1) the collection of bodily fluids or withdrawal of body fluids after initial venous or arterial access is established; (2) administration of medication or fluids; or (3) any other procedure involving the potential for occupational exposure to bloodborne pathogens due to percuatneious injuries from contaminated sharps.
Although OSHA states in the final rule that it does not intend these definitional changes to impose new requirements upon employers, such as hospitals and ASCs, they most certainly will require additional work. The definition changes will require employers to evaluate "sharps with engineered sharps injury protections," "needleless systems," and all other new medical devices that function as "engineering controls," and may require employers to modify their Plans to incorporate these technologies.

\section{Consideration and Implementation of New Technology}

In this change, OSHA intends to impose new obligations on employers whose businesses affect interstate commerce, and whose employees are exposed to bloodborne pathogens. Affected employers will include hospitals, ASCs, and other health care facilities, as well as pain management practices and other physician practices in many circumstances. The regulation requires employers to account for innovations in technological developments that reduce the risk of exposure incidents. Employers must consider and implement "appropriate commercially available and effective safer medical devices" designed to eliminate or minimize occupation exposure, on at least an annual basis. The consideration undertaken must be documented.

Unfortunately for hospitals and ASCs, the regulation does not offer much guidance as to how this consideration and implementation is to be conducted. The preamble to the regulation states only that a device will be considered to be "appropriate" if it will not jeopardize patient or employee safety, and is not medically contraindicated. OSHA further states that the determination of whether a device is "effective" should be based on a "reasonable judgment" that the device will make an exposure incident less likely. Nowhere, however, does OSHA indicate when it considers a device to be "available in the marketplace." Nor, does OSHA state what it will consider to be a "safer medical device."

This lack of guidance presents a host of uncertainties in the efforts of hospitals and ASCs to comply with the final rule. For example, at what point can technology be said to have established that it eliminates or reduces exposure to bloodborne pathogens, such that it must be reflected in the Plan? When does a device become recognized as "safer?" Additionally, when is a device considered "effective?" Is effectiveness tied to Food and Drug Administration approval? Further, at what point does a device become "available in the marketplace?" How many units must be on sale for this standard to be met? What efforts must a hos- 
pital or ASC undertake to acquire the device? Is there a cost limit? If the hospital or ASC determines that the device is "safer," "appropriate," "commercially available," and "effective," and thus must implement the use of the device, from a practical perspective, how can it force a non-employee physician to use such device. If it does force the physician to use the device, e.g. through the medical staff bylaws, what is the increased liability risk to the facility for a bad outcome? For now, the best course will be for hospitals and ASCs to fully document their determinations, and the reasoning for them.

\section{Employee Input}

In addition to requiring that employers, such as hospitals and ASCs, consider and implement new technologies, OSHA also requires that they solicit the input of their employees. Specifically, OSHA will require employers to seek input from non-managerial employees who are responsible for direct patient care, and who may be potentially exposed to injuries from contaminated sharps. Employees must be asked to identify, evaluate, and select effective engineering and work practice controls. The solicitation for input must be documented in a employer's Plan.

There are no specific procedures as to how an employer must obtain employee input. A hospital or ASC is afforded the flexibility to solicit input in the manner in which it deems appropriate. The steps taken to solicit input must be reasonable, however. OSHA suggests what reasonable steps may be. OSHA states that a dental office employing two hygienists for instance, may choose to have periodic conversations with the hygienists. A large hospital would likely find that an effective process for soliciting employee input requires the implementation of more formal procedures OSHA adds. Methods for soliciting employee input may include involvement in informal problem-solving groups; participation in safety audits; worksite inspections; exposure incident investigations; participation in the evaluation of devices through pilot testing; and involvement in a safety and health committee properly constituted and operated in conformance with the National Labor Relations Board.

\section{Recordkeeping}

Not only must hospitals and ASC now consider and implement new technologies and solicit employee input in the identification, evaluation, and selection of controls, they must also under the final rule, maintain a sharps injury log for the purpose of identifying high risk areas and for evaluating devices. The log must be maintained so as to protect the confidentiality of the injured employee. The log must contain at a minimum: (1) the type and brand of the device involved in the incident, (2) the department or work area where the exposure incident occurred, and (3) an explanation of how the incident occurred.

As with other requirements of the final rule, OSHA does not provide a sample or recommended format for the sharps $\log$. OSHA states in the preamble, that employers are permitted to determine the format in which the log is maintained (e.g. paper or electronic), and may include information in addition to that required by the standard so long as the privacy of injured workers is protected. Although, hospitals and ASCs may use the OSHA 300 Log of WorkRelated Injuries and Illnesses and the OSHA 301 Injury and Illness Incident Report to meet the sharps injury log requirements, provided that certain conditions are satisfied.

\section{CONCLUSION}

Congress and OSHA should be commended for acting to protect the country's health care workers by reducing their exposure to bloodborne pathogens. Despite this worthwhile endeavor, however, practical questions about implementing the new requirements are a source of major concern.

The House Committee on Education and the Workforce stated in legislative history to the Act that the statute was not meant to disturb the underlying flexible, performanceoriented nature of the Initial Standard. It also specifically stated that it "did not expect an OSHA inspector to substitute his judgment for that of the professional, clinical, and medical judgment of health care professionals responsible for patient safety." Only time will tell if OSHA will honor this Congressional intent.

The effective date of these revisions is April 18, 2001. Exposure Control Plans that are reviewed and updated on or after this date must incorporate these revised standards. The Act and the implementation regulations will begin to reshape practice in a matter of just a few weeks. 